Journal of Thermal Engineering, Vol. 7, No. 1, pp. 240-254, January, 2021

Yildiz Technical University Press, Istanbul, Turkey

\title{
NATURAL CONVECTION HEAT TRANSFER INSIDE HORIZONTAL CIRCULAR ENCLOSURE WITH TRIANGULAR CYLINDER AT DIFFERENT ANGLES OF INCLINATION
}

\author{
Akeel Abdullah Mohammed 1,*
}

\begin{abstract}
Numerical simulation study by using Fluent CFD software has been carried out to investigate the steady laminar natural convective heat transfer for air formed by heated inner equilateral triangular cylinder inside cold circular enclosure. The triangular cylinder was located at center of enclosure with four radius ratio $\mathrm{RR}=1.5,2,2.5$, and 3 ; and four inclination angles, $\theta=0^{\circ}$ (the base of triangle cylinder at bottom), $20^{\circ}, 40^{\circ}$ and $60^{\circ}$ (the base of triangle at top). All numerical calculations were performed in the range of Rayleigh number extends from $10^{3}$ to $10^{7}$. The fluid and temperature fields were represented in the form of streamlines and isotherms. Results show that, As Rayleigh number increases, the streamlines become more concentrated next to the walls and the center of vortex displays upward towards the central plane of enclosure. Also, there is no effect for the inclination angle of triangular cylinder on the peak values of local Nusselt number along the inner surface of circular cylinder except the positions of these peaks due to turning of thermal plumes.
\end{abstract}

Keywords: Natural Convection, Heat Transfer, Circular Enclosure, Triangular Cylinder

\section{INTRODUCTION}

Buoyancy effects around a circular enclosure contains concentrically heated triangular cylinder has considerable attention by many researchers due to its important practical engineering applications, such as the solar collectors, nuclear reactor applications, cooling of electronic devices, etc [1-14]. The outer surface of the enclosure is to reduce the heat transfer from the inner hot surface or to protect the inner body in harsh outdoor environment.

Especially, the following researchers are successful explanation in this field. Esam, [1] examined transversely oscillating frequency of the heated inner triangular cylinder on the heat transfer in a horizontal circular enclosure. The results showed that the oscillating inner cylinder and the oscillating eccentricity have a negative influence on the heat transfer rates at the outer cylinder. Varol et al. , [2] choice an inclined square cavity heated via corner heater with various lengths to study the phenomena of natural convection. One wall of the enclosure was isothermal and the other walls were adiabatic. They observed that the inclination angle and length of the corner heater have significant effects on average heat transfer rates. Ogut, [3] used water-based nanofluids in an inclined square enclosure with uniformly heated left vertical side and cooled right side, and the other sides were kept adiabatic. He showed that the heat transfer rate increases with increasing of particle volume fraction and Rayleigh number and it starts to decrease for a smaller inclination angle as heater length increases. Xu et al., [4] concluded that both the cross-section geometry and inclination angle of circular cylinder inside concentric triangular enclosure have insignificant effects on the heat transfer coefficients at constant aspect ratio. Zi-Tao et al., [5] found that the fluid flow and heat transfer characteristics from a horizontal coaxial triangular cylinder to its concentric circular enclosure are independent of Prandtl number when $\operatorname{Pr} \geq 0$.7. Revnic et al., [6] focused on the influences of magnetic field on natural convection inside a horizontal square enclosure exposed to heat generation and filled with a fluid-saturated porous medium. They showed that the diffusive heat transfer becomes significant with increase in Rayleigh number. Han Wang et al., [7] found that the vortexes located at the top of the rectangular cylinder and enclosed concentrically by circular enclosure have important effects 
on the average heat transfer rates, when the aspect ratio exceeds to 1.2. Sheikholeslami et al., [8] used $\mathrm{Cu}-$ water nanofluid in a cold outer circular enclosure containing a constant temperature hot inner sinusoidal circular cylinder under effect of magnetic field. They found that the average heat transfer rate increases with increasing of Rayleigh numbers and nanoparticle volume fraction. Khozeymehnezhad and Mirbozorgi, [9] made a comparison of natural convection around a hot circular cylinder with a hot square cylinder with different locations inside a cooled square enclosure. They showed that the rate of heat transfer from the enclosure which the circular cylinder is located inside is better than square cylinder at the same Rayleigh number. Roslan et al., [10] studied the conjugate free convection in a square enclosure containing a conductive polygon object with heated left wall, cooled right wall, and adiabatic horizontal walls. They concluded that the average heat transfer rate enhances as the size of the solid polygon increases, until it reaches its maximum critical value after which the heat transfer will decrease. Hussein and Rout, [11] studied this phenomenon inside rectangle cavity with a triangular roof with an insulated solid strip inserts at center of the cavity. They found that the solid strip has a considerable effect on the flow behavior and thermal field. Yuan et al. [12], studied the effect of different shapes (circular, elliptical, square, and triangular cylinder) inside cylindrical enclosure with or without surface radiation at relatively higher Rayleigh numbers $\geq 10^{5}$. It was observed that the surface radiation has important effects on the thermal performance as the reference temperature increases. Sharma and Kumar, [13] studied the natural convection around heated semi-circular cylinder placed at various incidences inside a square cavity. It was found that surface heat transfer coefficient increases, for all incidences, for $10^{4}$ Rayleigh number. Krunal and Manikandan, [14] studied laminar natural convection characteristics in a square enclosure with heated hexagonal block for non-Newtonian power law fluids. They observed that Nusselt number varies linearly with Grashof and Prandtl numbers; while convection heat transfer decreases for power law index value. Table 1 gives a summary of the literatures above and a scope of the present work. Alsabery, [15] analyzed two phase model for the conjugate natural convection of nanofluid inside square concentric annulus with heated left bottom corner and cooled right top corner of outer cavity. They concluded that the higher thermal conductivity of inner block reduces the high nano-particles concentration regions. Sivaraj and Sheremet, [16] studied the effect of magnetic field on the combined free convection and entropy generation of ferrofluid around a heated centered horizontal plate enclosed by a square cavity. They concluded that the heat transfer rate and entropy generation decrease as Hartmann number increases. Abbasi et al., [17] used $\mathrm{H}_{2} \mathrm{O}-\mathrm{Al}_{2} \mathrm{O}_{3}$ in an incinerator shaped cavity containing a heated source located at the lower of cavity. They concluded that the location of heat source plays a significant role in the heat transfer process. Geridonmez, [18] used $\mathrm{Fe}_{3} \mathrm{O}_{4}-\mathrm{H}_{2} \mathrm{O}$ ferrofluid in a porous enclosure under effect magnetic field, and concluded the natural convective decreases with reduction in Darcy number, and as the position of magnetic source located near to the left or top walls. Dogonchi et al., [19] used copper-water nanofluid in a porous media around uniformly hot rectangular cavity enclosed by cold circular cylinder to study the influence of magnetic field on the free convection heat transfer. The results show that the heat transfer process enhances with $\mathrm{Ra}, \mathrm{Da}$, and $\phi$, while it decreases as Ha and $\gamma$ increase.

The problem of natural convection heat transfer inside cold circular enclosure containing a hot concentric triangular cylinder has been studied theoretically by using CFD Ansys software, version 18.2. Velocity and temperature fields are obtained and discussed, and the effect of increasing the heat transfer rates is studied. The working fluid is air with $\operatorname{Pr}=0.71$. The present work gives an extension line to previous works that studied this problem but with high range of Rayliegh number extends from $10^{3}$ to $10^{7}$, four inclination angles for triangular cylinder $\left(0^{\circ}\right.$ - the apex of triangle at the top, $20^{\circ}, 40^{\circ}$, and $60^{\circ}$ - the apex of triangle at the bottom), and four radius ratio values $(1.5,2,2.5$, and 3). Table 1 represents summary of above literatures. 
Table 1. Summary of literatures.

\begin{tabular}{|c|c|c|c|}
\hline Authors & Geometry & Ra and Pr & Novelty \\
\hline Esam, [1] & Eccentric annulus & $\begin{array}{c}10^{4} \leq \mathrm{Ra} \leq 10^{5}, \\
\operatorname{Pr}=0.71\end{array}$ & $\begin{array}{l}\text { Study the effect of oscillating } \\
\text { of inner cylinder. }\end{array}$ \\
\hline Varol et al, [2] & Inclined square cavity & $\begin{array}{c}10^{3} \leq \mathrm{Ra} \leq 10^{6}, \\
\operatorname{Pr}=0.71\end{array}$ & Using of porous media. \\
\hline Ogut, [3] & $\begin{array}{c}\text { Inclined square } \\
\text { enclosure }\end{array}$ & $\begin{array}{c}10^{4} \leq \mathrm{Ra} \leq 10^{6} \\
\text { water-based nanofluids }\end{array}$ & $\begin{array}{l}\text { Using different types of } \\
\text { nanoparticles. }\end{array}$ \\
\hline Xu et al., [4] & $\begin{array}{l}\text { Circular cavity with } \\
\text { traingular inner cylinder }\end{array}$ & $\begin{array}{c}10^{3} \leq \mathrm{Ra} \leq 10^{6} \\
\operatorname{Pr}=0.71\end{array}$ & $\begin{array}{l}\text { Using different angles of } \\
\text { triangular cylinder inclination. }\end{array}$ \\
\hline Zi-Tao et al., [5] & $\begin{array}{l}\text { Circular enclosure with } \\
\text { inner traingular cylinder }\end{array}$ & $\begin{array}{l}10^{3} \leq \operatorname{Ra} \leq 10^{6} \\
10^{-2}<\operatorname{Pr}<10^{3}\end{array}$ & $\begin{array}{l}\text { Using wide range of Prandtl } \\
\text { number. }\end{array}$ \\
\hline Revnic et al., [6] & Square cavity & $\begin{array}{l}\mathrm{Ra}=10^{3} \& 10^{5} \\
\mathrm{Ha}=1 \& 1000\end{array}$ & $\begin{array}{l}\text { Using of magnetic field, heat } \\
\text { generation, and porous media. }\end{array}$ \\
\hline Wang et al., [7] & $\begin{array}{c}\text { Circular enclosure } \\
\text { having rectaular cylinder }\end{array}$ & $\begin{array}{c}10^{3} \leq \mathrm{Ra} \leq 10^{6} \\
\operatorname{Pr}=0.71\end{array}$ & $\begin{array}{l}\text { Using rectangular cylinder } \\
\text { inside circular enclosure. }\end{array}$ \\
\hline $\begin{array}{l}\text { Sheikholeslami et al., } \\
\text { [8] }\end{array}$ & $\begin{array}{l}\text { Circular enclosure with a } \\
\text { sinusoidal inner cylinder. }\end{array}$ & $\begin{array}{c}10^{3} \leq \mathrm{Ra} \leq 10^{5} \\
\mathrm{Cu}-\mathrm{H}_{2} \mathrm{O} \text { nano fluid. }\end{array}$ & $\begin{array}{l}\text { Using of sinusoidal circular } \\
\text { heated cylinder. }\end{array}$ \\
\hline $\begin{array}{l}\text { Khozeymehnezhad } \\
\text { and Mirbozorgi, [9] }\end{array}$ & $\begin{array}{l}\text { Square enclosure having } \\
\text { circular/square cylinder. }\end{array}$ & $\begin{array}{c}\mathrm{Ra}=10^{3}-10^{5} \\
\operatorname{Pr}=0.707\end{array}$ & $\begin{array}{l}\text { Using two shapes of inner } \\
\text { cylinder at different locations. }\end{array}$ \\
\hline Roslan et al., [10] & $\begin{array}{l}\text { Square enclosure with a } \\
\text { polygon inner object. }\end{array}$ & $\begin{array}{c}10^{3} \leq \mathrm{Ra} \leq 10^{6} \\
\operatorname{Pr}=0.71\end{array}$ & $\begin{array}{l}\text { Study of conjugate natural } \\
\text { convection heat transfer. }\end{array}$ \\
\hline Hussein et al., [11] & $\begin{array}{l}\text { Rectangle cavity with a } \\
\text { triangular roof. }\end{array}$ & $\begin{array}{c}10^{3} \leq \mathrm{Ra} \leq 10^{6} \\
\operatorname{Pr}=0.7\end{array}$ & $\begin{array}{l}\text { Using new geometry of } \\
\begin{array}{l}\text { enclosure with different } \\
\text { boundary conditions. }\end{array}\end{array}$ \\
\hline Yuan et al., [12] & $\begin{array}{l}\text { Circular enclosure with } \\
\text { different geometries of } \\
\text { inner cylinder }\end{array}$ & $\begin{array}{c}10^{3} \leq \mathrm{Ra} \leq 10^{5} \\
\operatorname{Pr}=0.7\end{array}$ & $\begin{array}{l}\text { Using of different geometries } \\
\text { of inner cylinder with radiation. }\end{array}$ \\
\hline $\begin{array}{l}\text { Sharma and Kumar, } \\
\text { [13] }\end{array}$ & $\begin{array}{l}\text { Semicircular cylinder } \\
\text { inside square enclosure }\end{array}$ & $\begin{array}{l}\mathrm{Ra}=10^{4} \\
\operatorname{Pr}=0.7\end{array}$ & $\begin{array}{l}\text { Using different angles of of } \\
\text { semi- circular. }\end{array}$ \\
\hline $\begin{array}{l}\text { Krunal and } \\
\text { Manikandan, [14] }\end{array}$ & $\begin{array}{l}\text { Hexagonal solid cylinder } \\
\text { inside square cavity }\end{array}$ & $\begin{array}{c}10^{3} \leq \mathrm{Gr} \leq 10^{6} \\
1 \leq \operatorname{Pr} \leq 100\end{array}$ & Using of non-Newtonian fluid \\
\hline Alsabery et al., [15] & $\begin{array}{l}\text { Concentric square } \\
\text { annulus }\end{array}$ & $\begin{array}{r}0 \leq \phi \leq 0.04 \\
10^{2} \leq R a \leq 10^{6}\end{array}$ & $\begin{array}{ll}\text { Using conjugate free } \\
\text { convection }\end{array}$ \\
\hline $\begin{array}{l}\text { Sivara and, Sheremet, } \\
\text { [16] }\end{array}$ & $\begin{array}{c}\text { Square cavity containing } \\
\text { horizontal plate }\end{array}$ & $\begin{array}{c}\mathrm{Ha}=0-100 \\
\phi=0.01-0.04\end{array}$ & $\begin{array}{l}\text { 1. Using nanofluid and } \\
\text { magnetic field. }\end{array}$ \\
\hline Dogonchi et al., [19] & $\begin{array}{c}\text { Hot rectangular cavity } \\
\text { enclosed by cold circular } \\
\text { cylinder }\end{array}$ & $\begin{array}{c}\left.10^{3} \leq R a \leq 10^{5}\right) \\
0 \leq H a \leq 50 \\
10^{-3} \leq D a \leq 10^{-1} \\
0 \leq \gamma \leq \pi / 3 \\
0 \leq \phi \leq 50^{0}\end{array}$ & $\begin{array}{l}\text { 1. Using nanofluid inside } \\
\text { porous media enclosure } \\
\text { Under influence of magnetic } \\
\text { field. } \\
\text { 2. Using of wide ranges of Ra, } \\
\mathrm{Da}, \mathrm{Ha}, \gamma \text {, and } \phi\end{array}$ \\
\hline Present work & $\begin{array}{l}\text { Hot triangular inner } \\
\text { cylinder enclosed by } \\
\text { cold circular enclosure }\end{array}$ & $\begin{array}{c}10^{3} \leq \mathrm{Ra} \leq 10^{7} \\
\operatorname{Pr}=0.7\end{array}$ & $\begin{array}{l}\text { Using four angles of triangular } \\
\text { cylinder inclination }\left(0^{\circ}-60^{\circ}\right) \\
\text { with high Rayleigh number } \\
\mathrm{Ra}=10^{7} \text {, and four radius ratios }\end{array}$ \\
\hline
\end{tabular}

\section{THEORY}

Figure 1 shows schematically the physical domain and coordinate system for the present problem. The side walls of inner triangular cylinder are maintained at constant heat flux, and outer cylinder is insulated. $\theta$ is the local 
coordinate system along the circle, respectively, and gravity is assumed acting downwards. The outer and inner cylinders are maintained at $T_{c}$ and $T_{h}$ respectively, where $T_{h}$ is higher than $T_{c}$. The driving force of natural convection is caused by the temperature gradient, $T_{h}-T_{c}$. The characteristic length $\mathrm{L}$ is chosen as the gap between the circle and the circumscribed. circle of the equilateral triangle, $L=R_{o}-R_{i}$, and the radius ratio is the ratio of the outer radius to the inner radius, $\mathrm{RR}=R_{o} / R_{i}$.

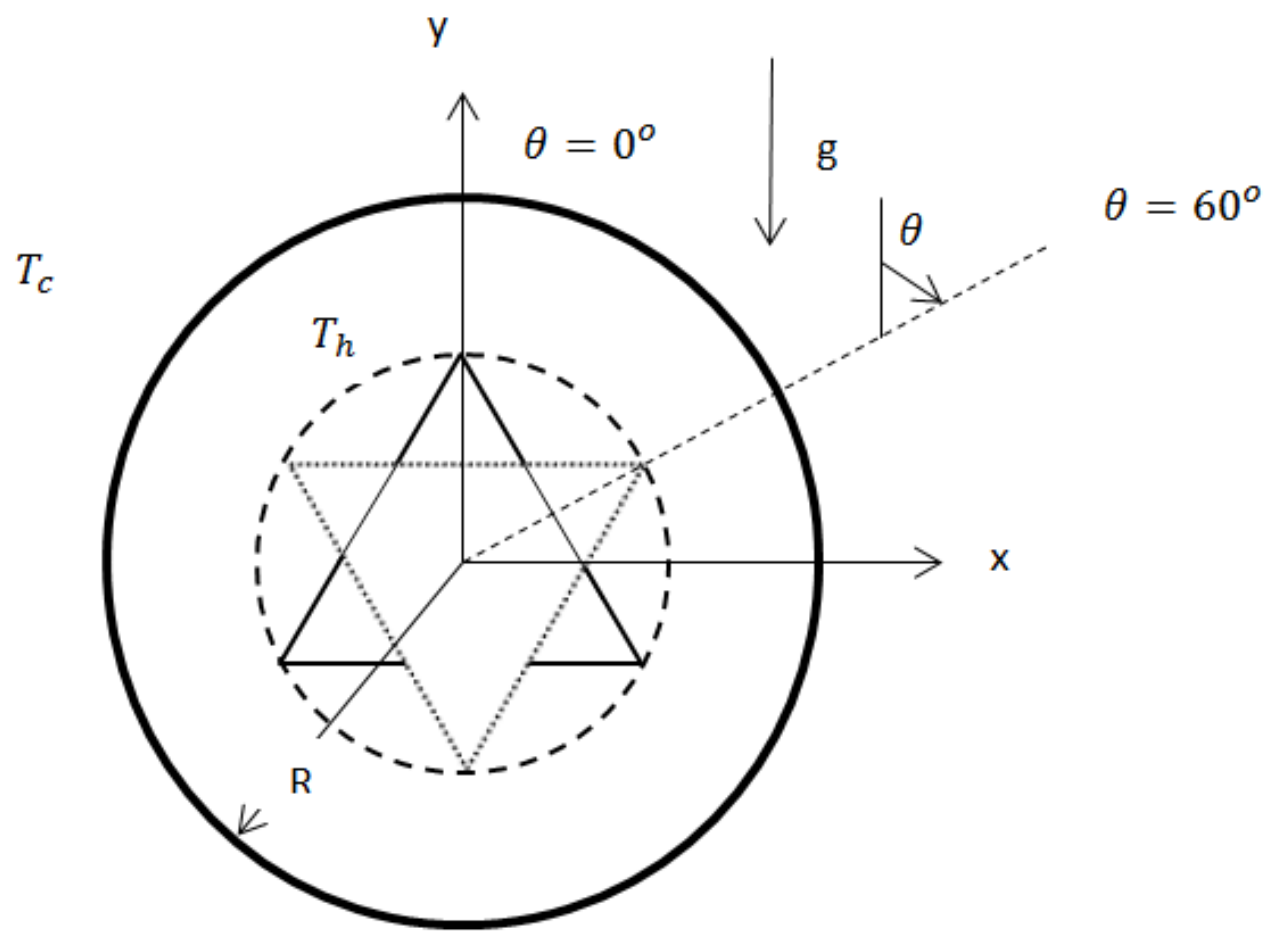

Figure 1. Physical domain of present work.

The dimensionless governing equations of $2 \mathrm{~d}$, laminar, incompressible buoyancy-induced flows with Boussinesq approximation and constant fluid properties are [7, 20]:

$$
\begin{gathered}
\frac{\partial U}{\partial X}+\frac{\partial V}{\partial Y}=0 \\
U \frac{\partial U}{\partial X}+V \frac{\partial U}{\partial Y}=-\frac{\partial P}{\partial X}+\frac{\partial^{2} U}{\partial X^{2}}+\frac{\partial^{2} U}{\partial Y^{2}} \\
U \frac{\partial V}{\partial X}+V \frac{\partial V}{\partial Y}=-\frac{\partial P}{\partial X}+\frac{\partial^{2} V}{\partial X^{2}}+\frac{\partial^{2} V}{\partial Y^{2}}+\frac{R a}{P r} T^{+} \\
U \frac{\partial T^{+}}{\partial X}+V \frac{\partial T^{+}}{\partial Y}=\frac{1}{P r}\left(\frac{\partial^{2} T^{+}}{\partial X^{2}}+\frac{\partial^{2} T^{+}}{\partial Y^{2}}\right)
\end{gathered}
$$

The dimensionless variables can be written as follows:

$$
X=\frac{x}{L}, Y=\frac{y}{L}, U=\frac{u L}{\vartheta}, V=\frac{v L}{\vartheta}, T^{+}=\frac{T-T_{C}}{T_{h}-T_{c}}, P=\frac{(p+g \rho y) L^{2}}{\rho \vartheta^{2}}
$$


where $T_{h}$ and $T_{c}$ are the hot and cold temperatures for the inner and outer cylinders; respectively, and $\mathrm{L}$ is the characteristic length, $\mathrm{L}=\mathrm{R}_{\mathrm{o}}-\mathrm{R}_{\mathrm{i}}$.

The non-dimensional boundary conditions are represented by:

1. $\mathrm{U}=\mathrm{V}=0$, no-slip boundary conditions are applied at all enclosure walls.

2. $T^{+}=0$ at the inner walls of the circular enclosure.

3. $T^{+}=1$ at the surface of the inner triangular cylinder.

In the present study two parameters that govern this problem which are the Prandtl and Rayleigh numbers. The air is the tested fluid $(\mathrm{Pr}=0.71)$. The Rayleigh number varies within a laminar range up to $\mathrm{Ra}=10^{7}$. The local and average Nusselt number along the inner surface of outer circular cylinder is given; respectively, as follows:

$$
\begin{aligned}
& \left.N u=\frac{\partial T^{+}}{\partial n}\right]_{\text {outer wall }} \\
& \overline{N u}=\frac{1}{2 \pi} \int_{0}^{2 \pi} N u d \varphi
\end{aligned}
$$

There is no doubt that the average Nusselt numbers along the inner and outer cylinders are equal at steady state condition, so we can depending only on equation (6) without needing to find it on the inner cylinder. Rayleigh number is calculated based on the characteristic length as follows:

$$
R a=\frac{g \beta L^{3}\left(T_{h}-T_{C}\right)}{\alpha_{f} \vartheta_{f}}
$$

\section{Mesh specifications}

Numerical simulation by ANSYS FLUENT software (version18.2) was used to investigate the convective heat transfer for air formed by inner hot equilateral triangular cylinder inside cold circular enclosure. Figure 2 shows the values of Nusselt number for different grid sizes for $\mathrm{RR}=3, \mathrm{Ra}=10^{5}, \theta=0^{\circ}$. As shown in this figure that the increasing of grid sizes greater than 14000 gives nearly identical results. So, the grid size of domain was chosen as 14,000 elements and 14070 nodes. The size function is curvature with angle of $18^{\circ}$ and the relevance center is fine with minimum face size $2.0645 \times 10^{-5}$ and growth rate is 1.2 with maximum face size $2.0645 \times 10^{-3} \mathrm{~m}$ and growth rate 1.2. Span angle center with minimum size $2.0645^{*} 10^{-5} \mathrm{~m}$ and curvature normal angle $18^{\circ}$. Mesh inflation is smooth transition with transition ratio 0.272 and maximum layers are two. Face meshing is made by using quadrilaterals method with 200 internal number of divisions, see Figure 3.

\section{Code validation}

The work results of $\mathrm{Xu}$ et al. [4] have been used for the validation of the current simulation for streamlines and isotherms contours; respectively, at $\mathrm{RR}=2$ and $\mathrm{Ra}=10^{3}$ and $10^{6}$ as shown in Figure 4. It is shown that the behavior and trend of temperature field and flow pattern obtains for present work is similar to the case study of [4] except at $\mathrm{Ra}=10^{3}$ for isotherms contour, there is a slight difference. The temperature field in the present work at this value of Rayleigh number seems to be smooth and circle because of the weak free convection currents and the dominant conduction heat transfer.

\section{RESULTS AND DISCUSSION}

A numerical analysis is performed to obtain a natural convection heat and flow characteristics in a circular enclosure containing concentric triangular. Prandtl number is taken as 0.71 . Constant radius ratio was taken (RR $=1.5$, 2, 2.5, and 3) and five different Rayleigh numbers $\left(\mathrm{Ra}=10^{3}-10^{7}\right)$ were considered. The triangular cylinder is clock wisely rotated about its center for different four angles $\theta=0^{\circ}$ (the base of triangle at the bottom), 20, $40^{\circ}$, and $60^{\circ}$ (the base of triangle at the top). 
Journal of Thermal Engineering, Research Article, Vol.7, No. 1, pp. 240-254 January, 2021

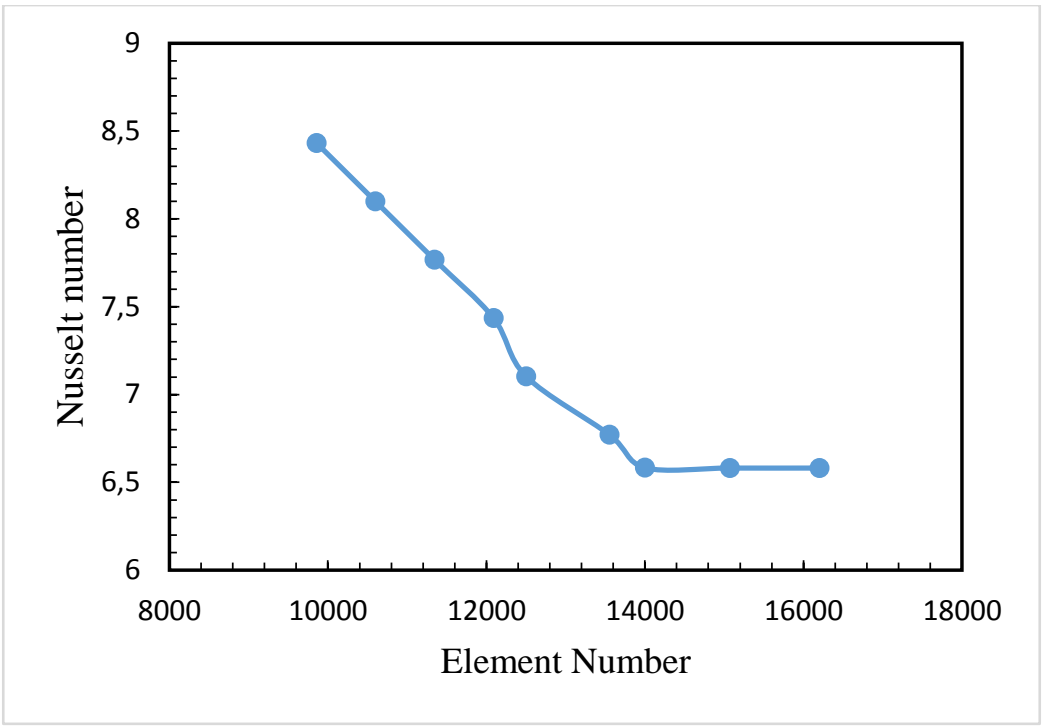

Figure 2. Average Nusselt number for different grid sizes, $\mathrm{RR}=3, \mathrm{Ra}=10^{5}, \theta=0^{\circ}$.

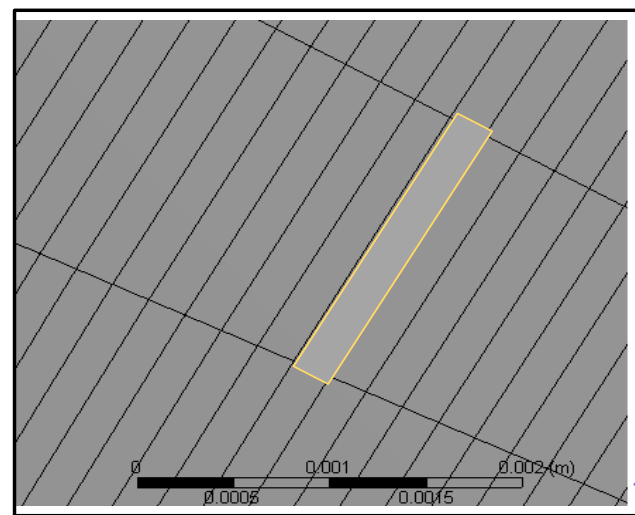

a. Cell geometry between one side of the triangle and the outer circle.

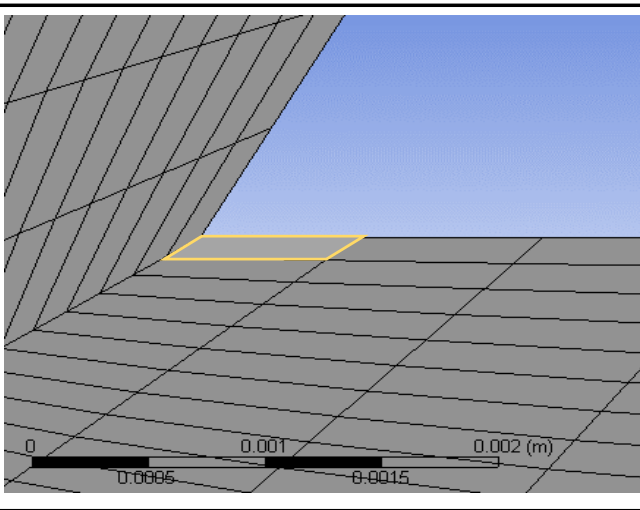

b. Cell geometry between corner of the triangle and the outer circle.

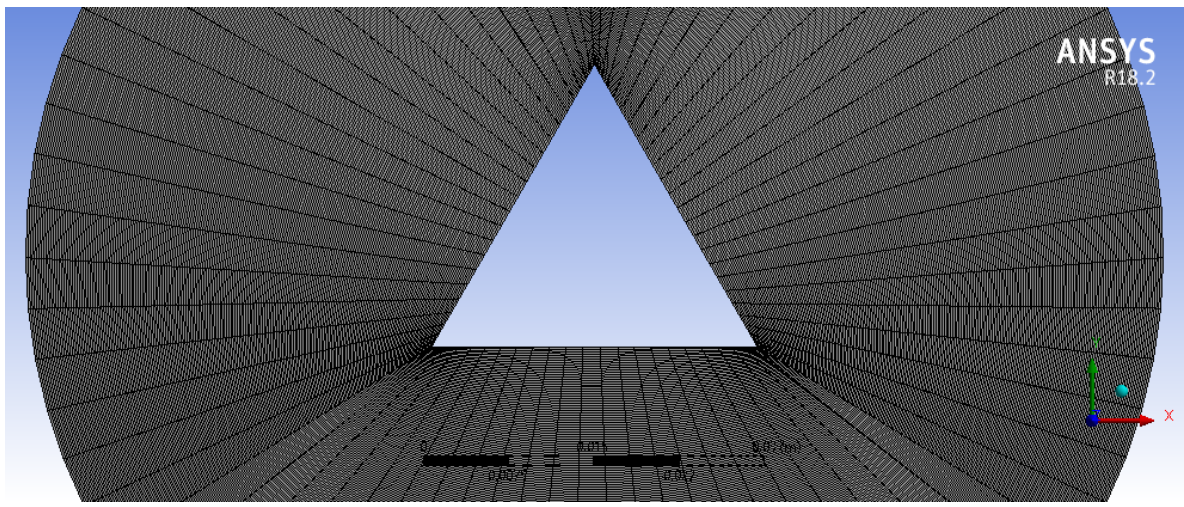

c. Grid geometry

Figure 3. Mesh geometry. 


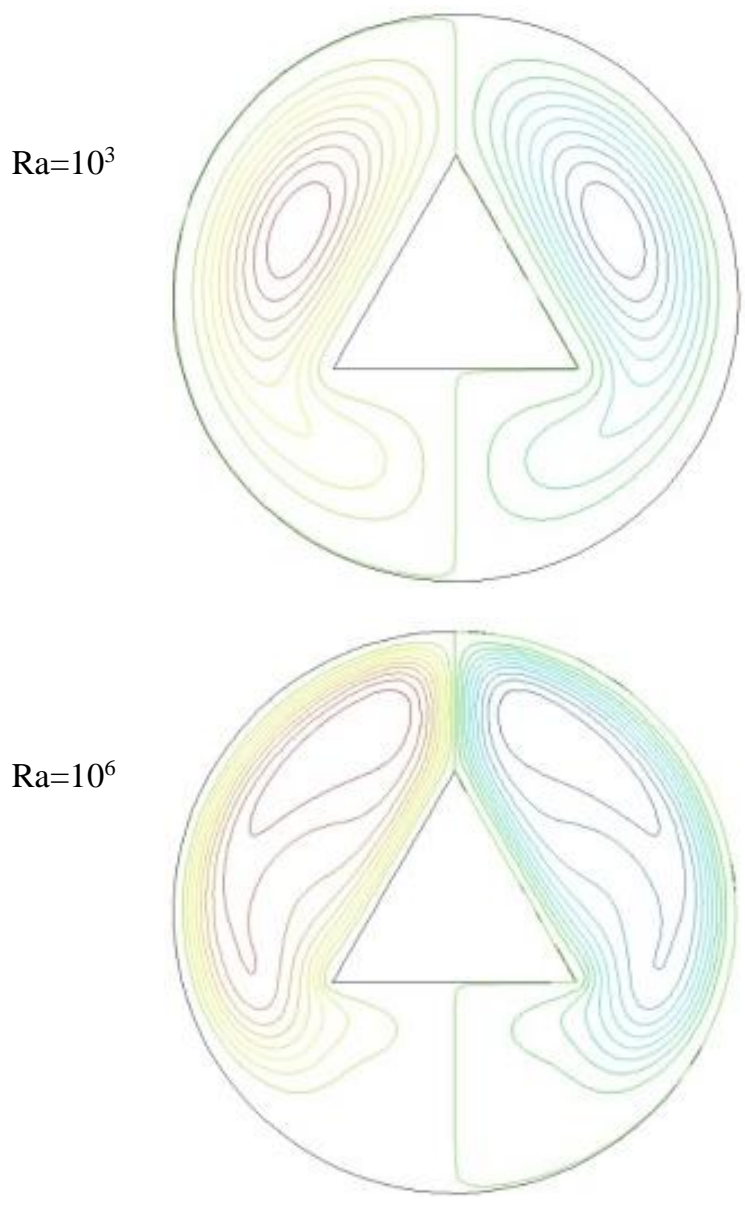

a. Streamlines contour
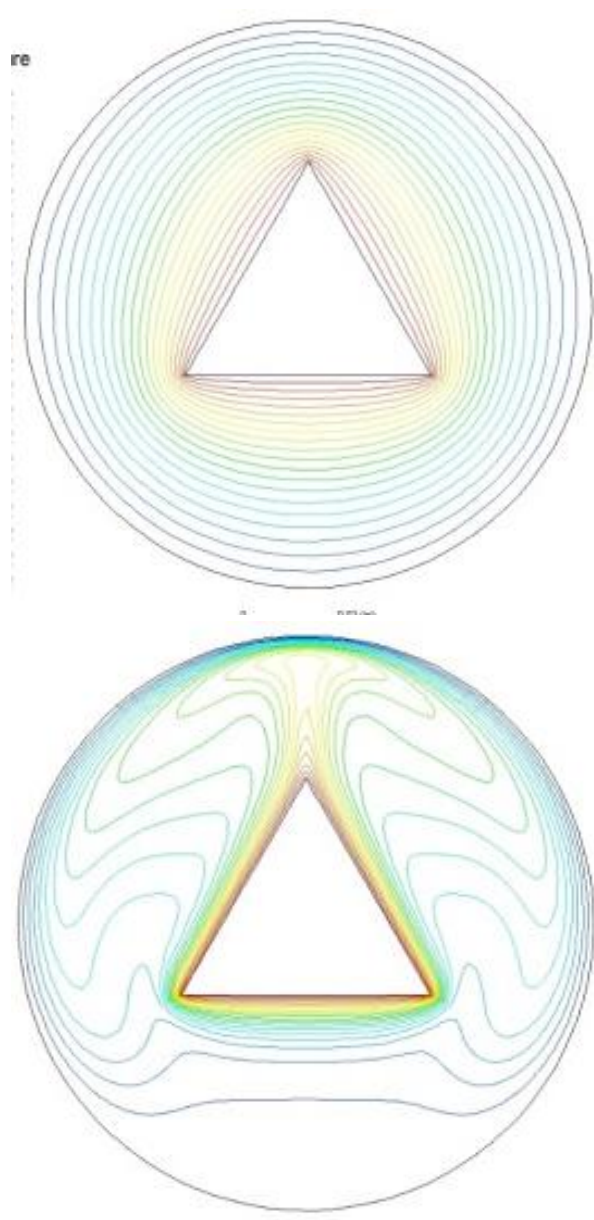

b. Isotherms contour

Figure 4. Streamlines and isotherms for present numerical results according to case study of [68].

\section{Streamline maps}

The streamlines through the gap between the heated triangular cylinder and cold outer circular enclosure at $\theta=0^{\circ}$ and $\mathrm{Ra}=10^{3}, 10^{4}, 10^{5}, 10^{6}$, and $10^{7}$ for radius ratios $\mathrm{RR}=3,2.5,2$, and 1.5; respectively, is shown in Figure 5. The array of subfigures is from left to right with ascending Ra and descending RR. In general, the air near the triangular wall is heated and rises upward then cooled downward along the outer cylinder. As a result, a main recirculating cell happen in each left and right region. Its center is located at the upper region of enclosure at each side. Where Rayleigh numbers increase, the streamlines become more concentrated next to the walls and the center of vortex displays upward towards the central plane of enclosure. The distortion occurs in the streamlines as radius ratio decreases. It is shown also that the cell patterns for $\mathrm{Ra}=10^{6}$ and $10^{7}$ are relatively different from those for $\mathrm{Ra}=10^{3}, 10^{4}$ and $10^{5}$ because the high strength of natural convection makes the streamlines to be more aligned.

The effect of inclination angle of triangular cylinder on the streamline's patterns for all values of radius ratio and at constant value of Rayleigh number $\left(\mathrm{Ra}=10^{5}\right)$ is shown in Figure 6, in which the array of subfigures is from left to right with ascending $\theta$ and descending RR. It is noticed that the asymmetric flow appears on each side of triangular cylinder as the inner triangle is deviated from $\theta=0^{\circ}$ (the base of triangle at bottom), towards $\theta=60^{\circ}$ (the base of triangle at top) because of asymmetric configuration about the vertical plane of enclosure. At $\theta=40^{\circ}$, RR=2, and $\mathrm{Ra}=10^{6}$, the main recirculating cell in the left upper and lower regions separates into two vortex cores. Then, the right main recirculating cell separates also into two vortex cores where $\theta$ increases to $60^{\circ}$ with large vortex core lies below 
of triangle base and small vortex core lies up of triangle base. The flow patterns become symmetric at $\theta=60^{\circ}$ for all cases because of symmetric configuration. The effect of the inclination angle becomes more considerable as the radius ratio decreases. The separation of boundary layer near the left vertex of the triangular cylinder is happen to produce a small recirculating cell at $\theta=20^{\circ}$ if the radius ratio decreases to 1.5 . The boundary layer separation becomes more pronounced with increasing Rayleigh number and decreasing radius ratio.

a

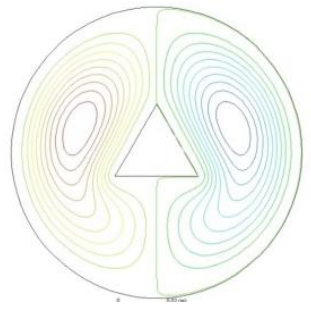

b
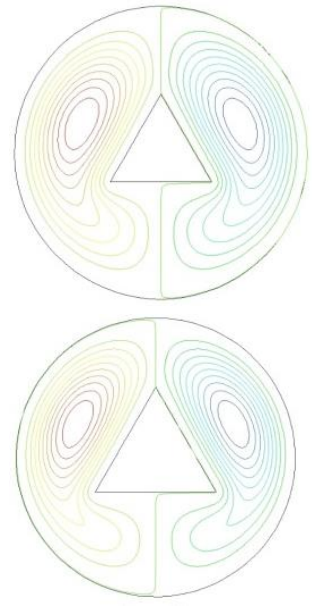

d

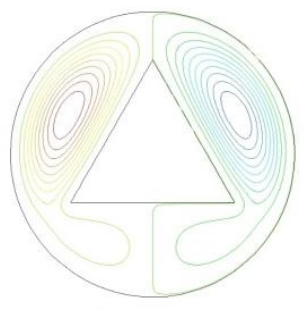

$\mathrm{Ra}=10^{3}$
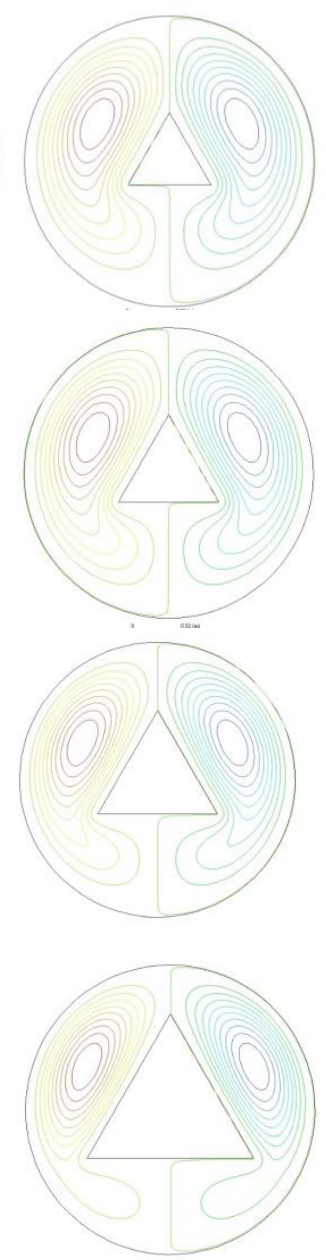

$\mathrm{Ra}=10^{4}$
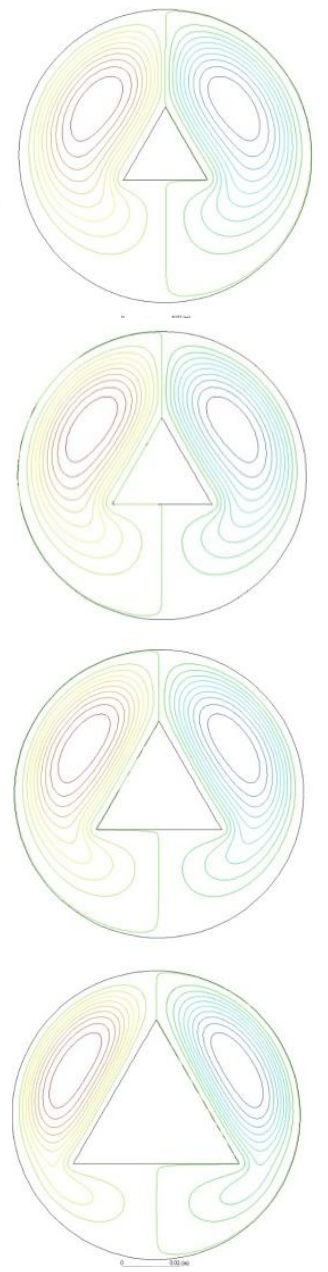

$\mathrm{Ra}=10^{5}$
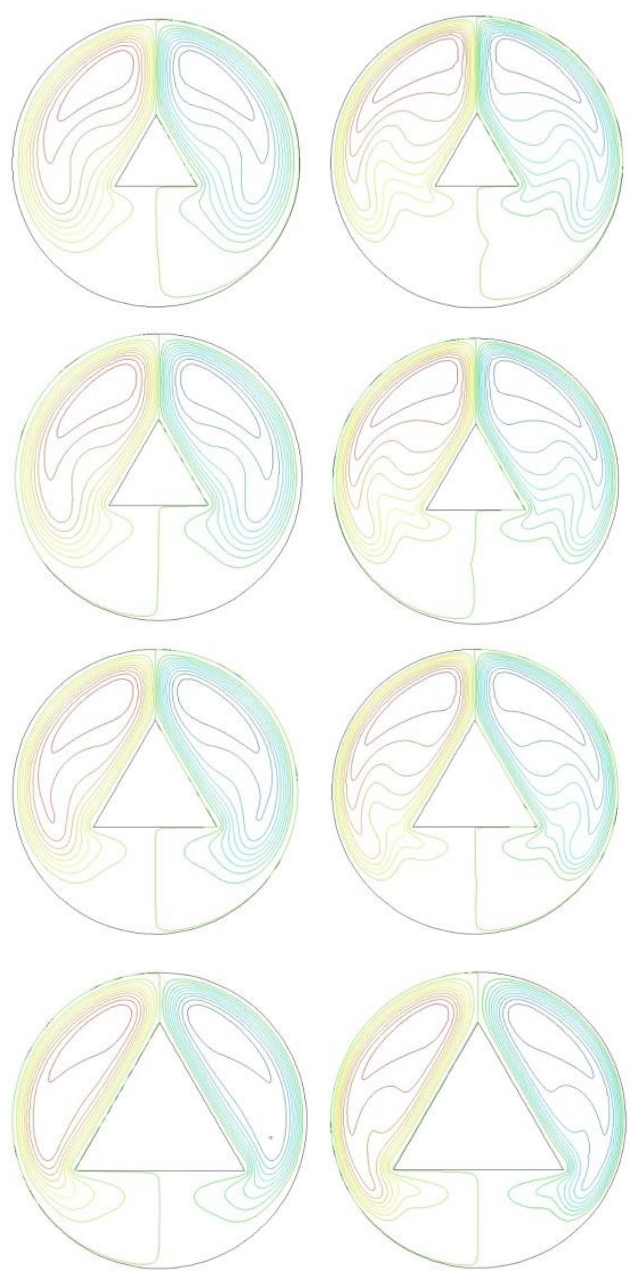

$\mathrm{Ra}=10^{6}$

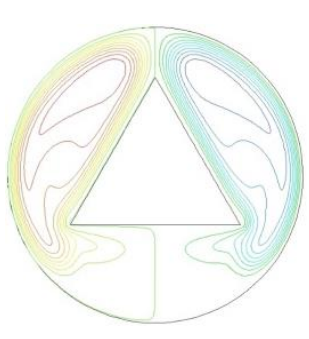

$\mathrm{Ra}=10^{7}$

Figure 5. Streamlines for (a) $R R=3.0$, (b) $R R=2.5$, (c) $R R=2$, and (d) $R R=1.5$ at $\theta=0^{\circ}$ and various $R a$.

\section{Isotherms map}

The temperature fields distribution (isotherms) for different values of Rayleigh number and radius ratio of concentric annulus with hot inner triangular cylinder at $\theta=0^{\circ}$ and outer circular enclosure are shown in Figure 7 with the same arrangement as Figure 5. Generally, the temperature fields are strongly dependent on the convection flow patterns. It is clear from figure that the thermal field is symmetric about the vertical line of enclosure center. At low Rayleigh number $\left(\mathrm{Ra}=10^{3}\right)$, conduction is the dominant factor of heat transfer process because of the weak recirculation and the low natural convection contribution. As a result, the physical behavior of temperature fields at any radius ratio are close to the case of pure conduction pattern, and the temperature contour are nearly concentric circles. It is obvious that the thermal boundary layer along the hot triangle cylinder separate away from the heated surface near the apex of triangle as Rayleigh number increases more than $10^{3}$. The flow strongly hits the top wall of 
the cold circular cylinder, which leads to produce a thin thermal boundary layer in this region and a thermal plume will form above the apex of triangle. It starts at $R a=10^{4}$ and developed to be more remarkable at $R a \geq 10^{5}$. The plume reaches to a maximum length at $R a=10^{7}$ at which the temperature fields is nearly horizontal flat under the hot cylinder for all radius ratio, and this region becomes colder because the dominant conduction heat transfer. It is clearly that at constant value of Rayleigh number, the thermal plum length is more decreased with decreasing radius ratio at expense increasing the isotherm lines under the base of triangular cylinder (i.e., decreasing of conduction heat transfer at this region of enclosure).

a

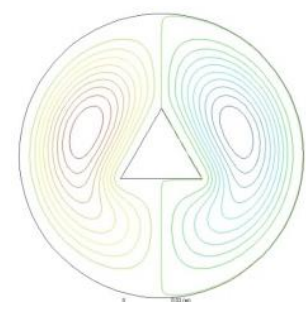

b

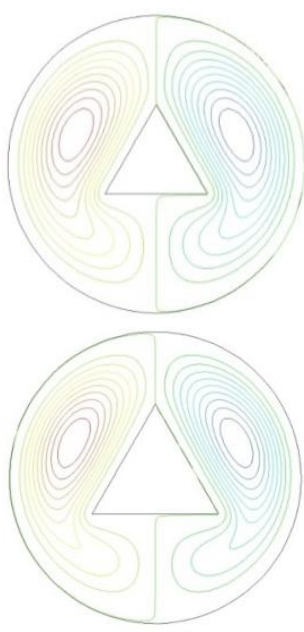

$\mathrm{d}$

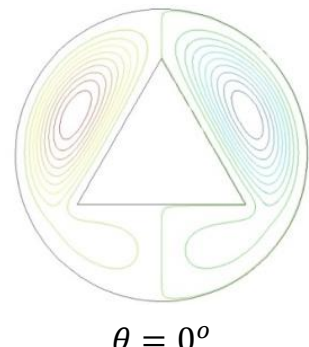

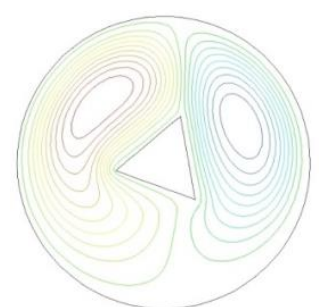
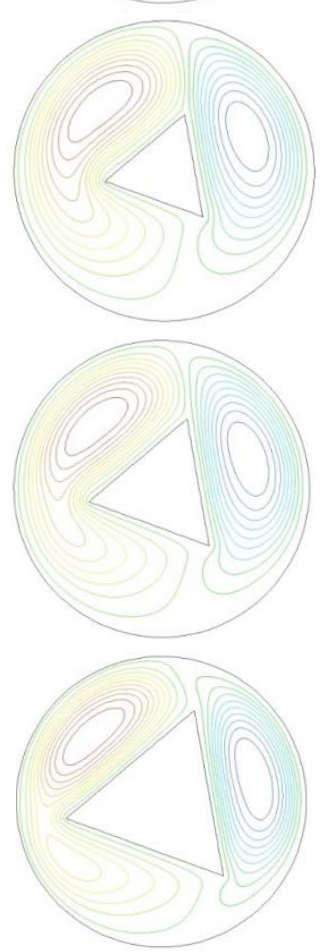

$\theta=20^{\circ}$
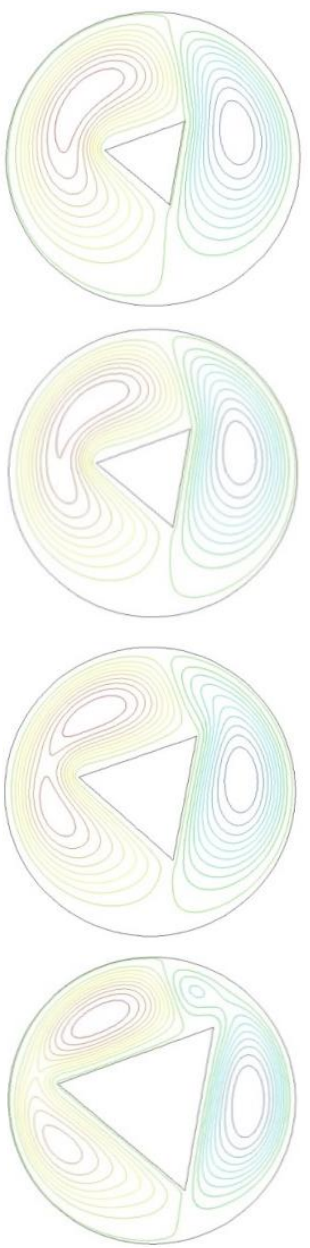

$\theta=40^{\circ}$
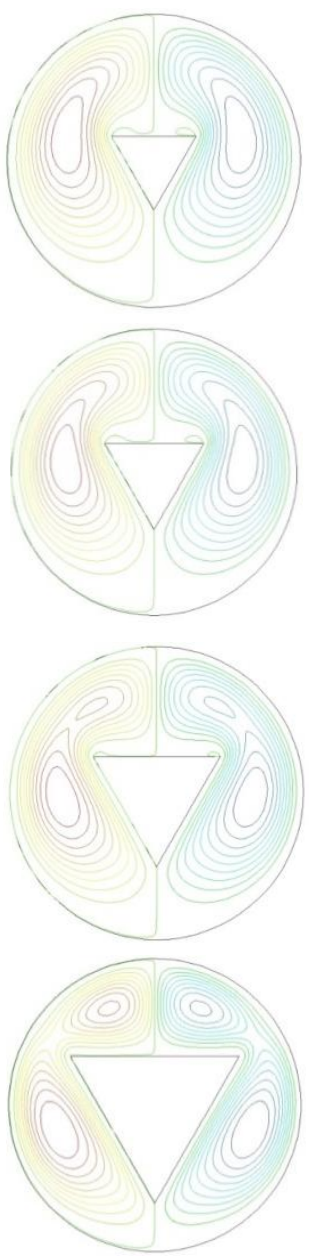

$\theta=60^{\circ}$

Figure 6. Streamlines for (a) $R R=3.0$, (b) $R R=2.5$, (c) $R R=2$, and (d) $R R=1.5$ at different inclination angles and $\mathrm{Ra}=10^{5}$.

The isotherm contours at $R a=10^{5}$ and for different values of radius ratio and inclination angle are presented in Figure 8 with the same arrangement as Figure 7. It is clear that the thermal plum deviates towards right hand side of vertical axis of enclosure at $\theta=20^{\circ} \& 40^{\circ}$ and return to the mid of enclosure at $\theta=60^{\circ}$ for all values of radius ratios. The conduction heat transfer mode is dominated at the bottom wall of circular cylinder for all radius ratios and inclination angles because of weaken buoyancy effects and unaffected thermal field at this region.

\section{Local nusselt number}

The effect of Rayleigh number on distribution of the local Nusselt number along the inner surface of outer circular cylinder for $\theta=0^{\circ}$ (base of triangle at the bottom), $\mathrm{RR}=1.5$ and 3 is shown in Figure 9-a \& b; respectively. 
As can be shown for all radius ratios that the values of local Nusselt number increase greatly as Rayleigh number increases due high convection heat transfer in the upper region of enclosure except in the region bounded between $\varphi=130^{\circ}$ to $230^{\circ}$ (lower region of enclosure) because of dominant conduction heat transfer. It is observed that two peaks for the local Nusselt number are noticed at the top points $\left(\varphi=0^{\circ}\right.$ or $\left.360^{\circ}\right)$ for $\operatorname{Ra} \geq 10^{4}$ due to generating of the thermal plumes that are showed in Figure 7. While at $\mathrm{Ra}=10^{3}$ there is no thermal plum inside the enclosure and the isotherms lines seem to be circular, so the local Nusselt number distribution is nearly flat especially at $\mathrm{RR}=2.5$ and 3 .

The influence of inclination angle of triangular cylinder on the distribution of local Nusselt number along the inner surface of outer cylinder for $\mathrm{RR}=2$ and 3 at $\mathrm{Ra}=10^{5}$ is shown in Figure 10-a and b; respectively. Generally, there is no effect for the inclination angle on the peak values of Nusselt number except the positions of these peaks due to turning of thermal plumes. It is noticed that, the peak position deviates towards the lower regions of outer cylinder as inclination angle of triangular cylinder changes from $60^{\circ}$ to $20^{\circ}$. This deviation increases as radius ratio increases. On the other hand, the minimum value of Nusselt number deviates towards the region bounded between $\varphi=240^{\circ}$ to $300^{\circ}$ (left side of enclosure). As explained before in Figure 6, the rotation of the triangular cylinder strengthens the vortex on the right-hand side of triangular cylinder and weakens it on the other side. This leads to strongly increasing the local Nusselt number on the right-hand side and decreasing it on the other side.

a

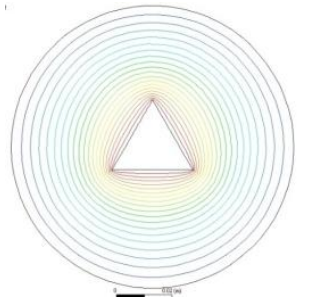

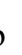
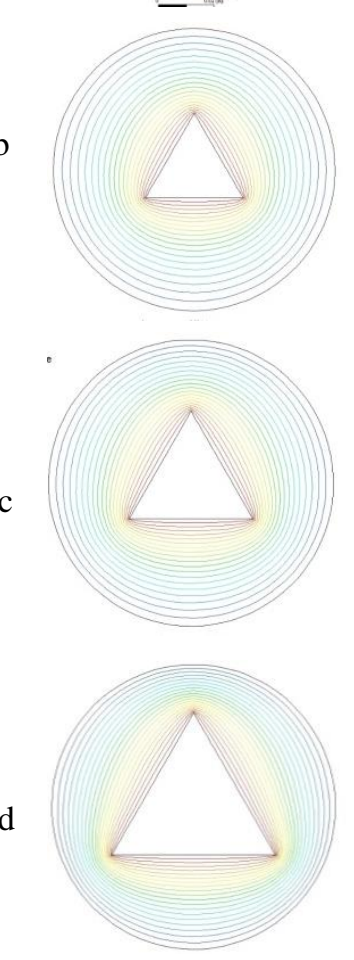

$\mathrm{Ra}=10^{3}$
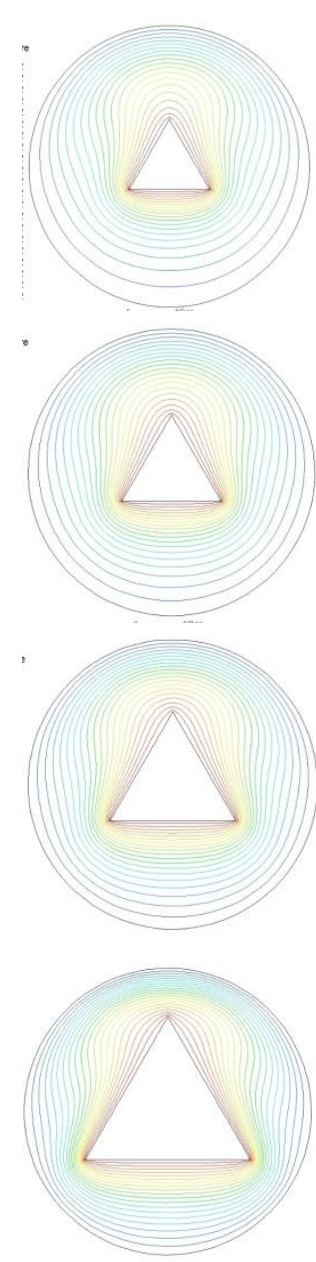

$\mathrm{Ra}=10^{4}$
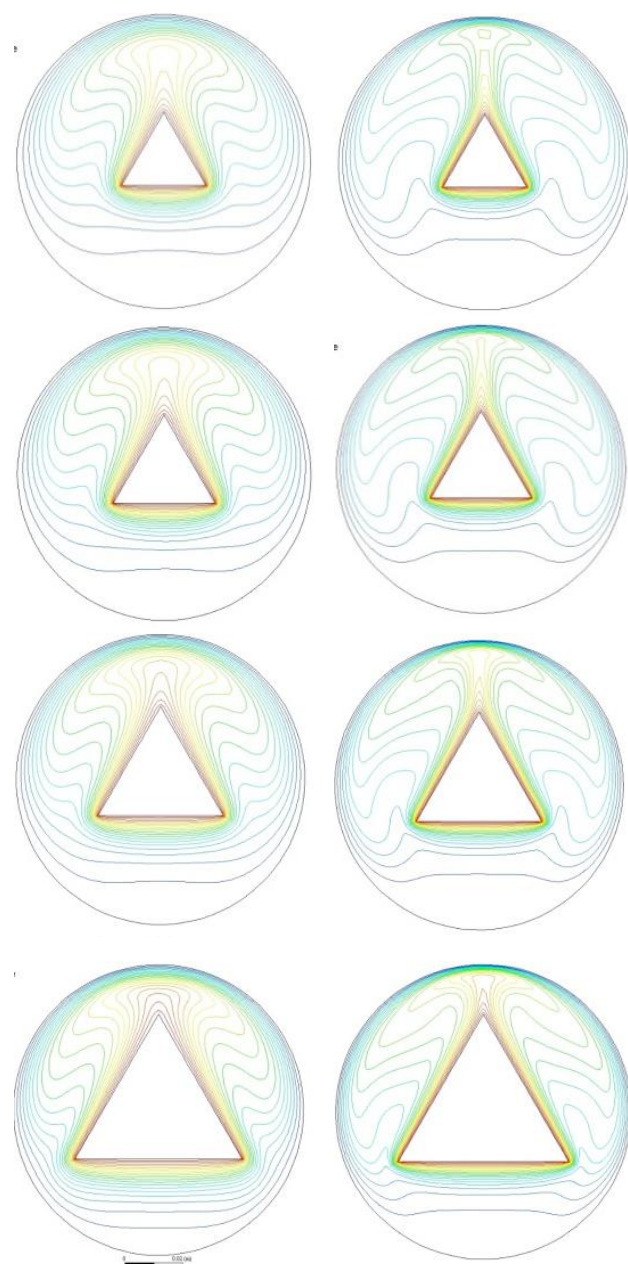

$\mathrm{Ra}=10^{5}$
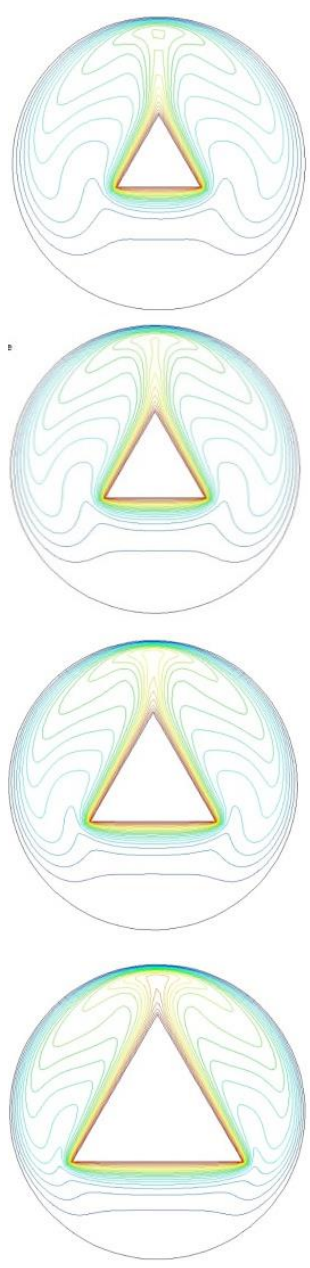

$\mathrm{Ra}=10^{6}$
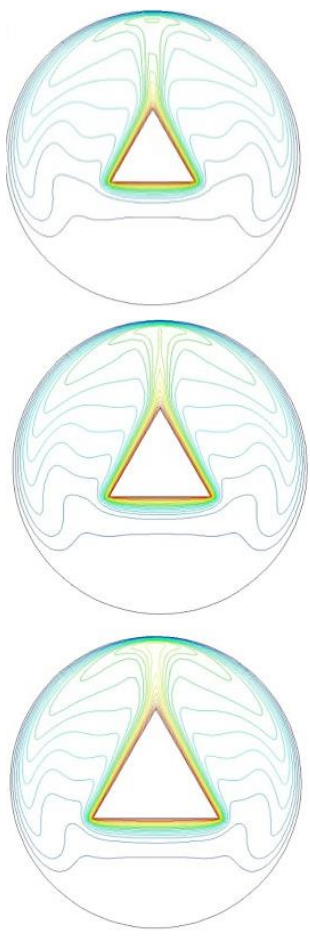

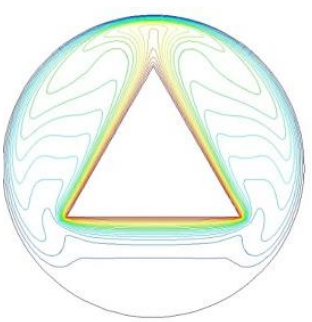

$\mathrm{Ra}=10^{7}$

Figure 7. Isotherms for (a) $R R=3.0$, (b) $R R=2.5$, (c) $R R=2$, and (d) $R R=1.5$ at $\theta=0^{\circ}$ and different Rayleigh numbers. 
a

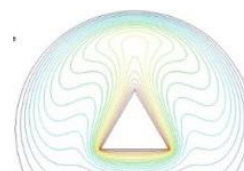

b

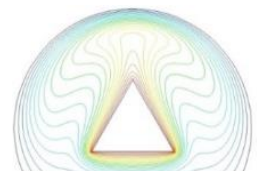

$\mathrm{c}$

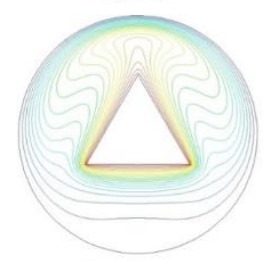

d

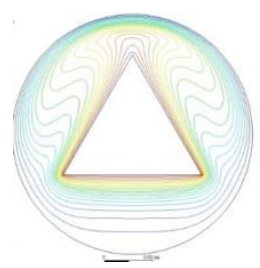

$\theta=0^{\circ}$
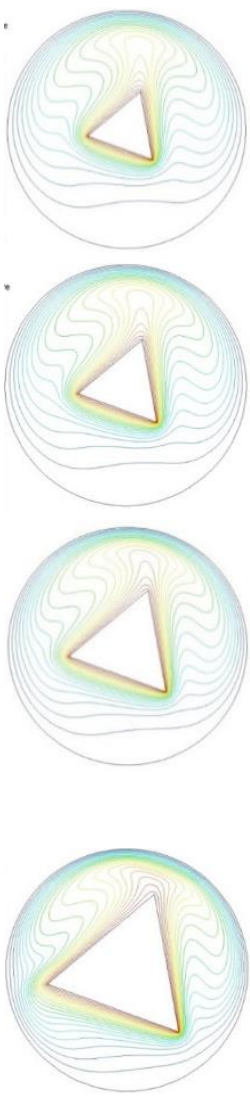

$\theta=20^{\circ}$
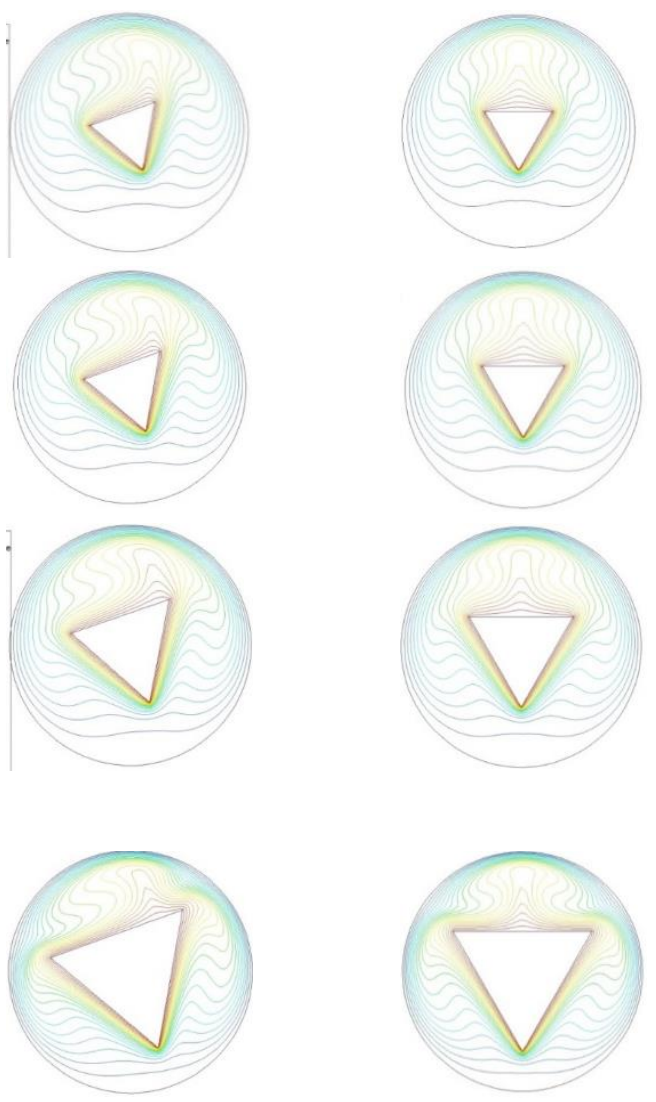

$\theta=40^{\circ}$

Figure 8. Isotherms for (a) $R R=3.0$, (b) $R R=2.5$, (c) $R R=2$, and (d) $R R=1.5$ at different inclination angles and $\mathrm{Ra}=10^{5}$.

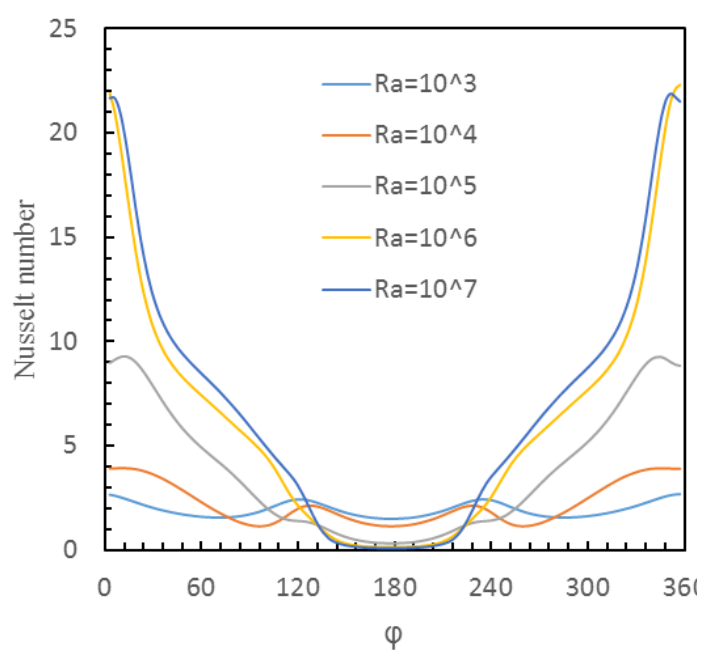

(a) $\mathrm{RR}=1.5$

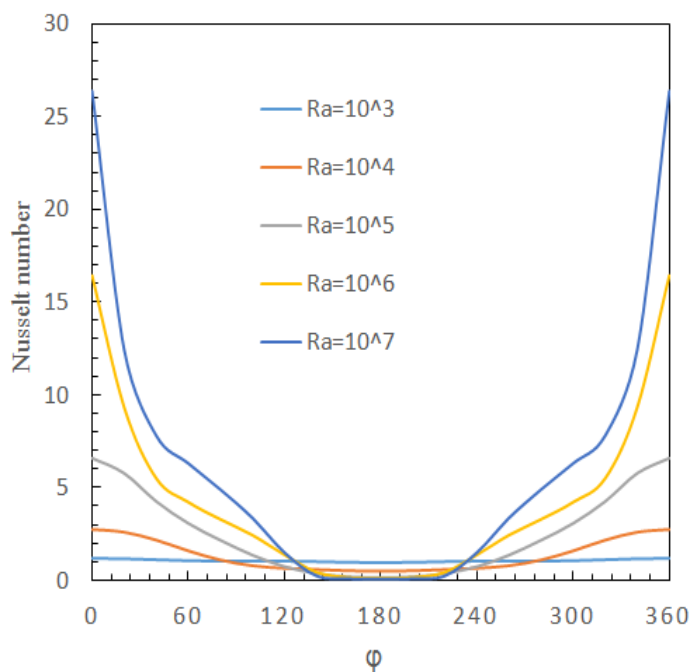

(b) $\mathrm{RR}=3$

Figure 9. Effect of Rayliegh number on local Nusselt number distribution along the inner surface of outer circular cylinder at angle of triangular cylinder $\theta=0^{\circ}$. 
Journal of Thermal Engineering, Research Article, Vol. 7, No. 1, pp.240-254, January, 2021

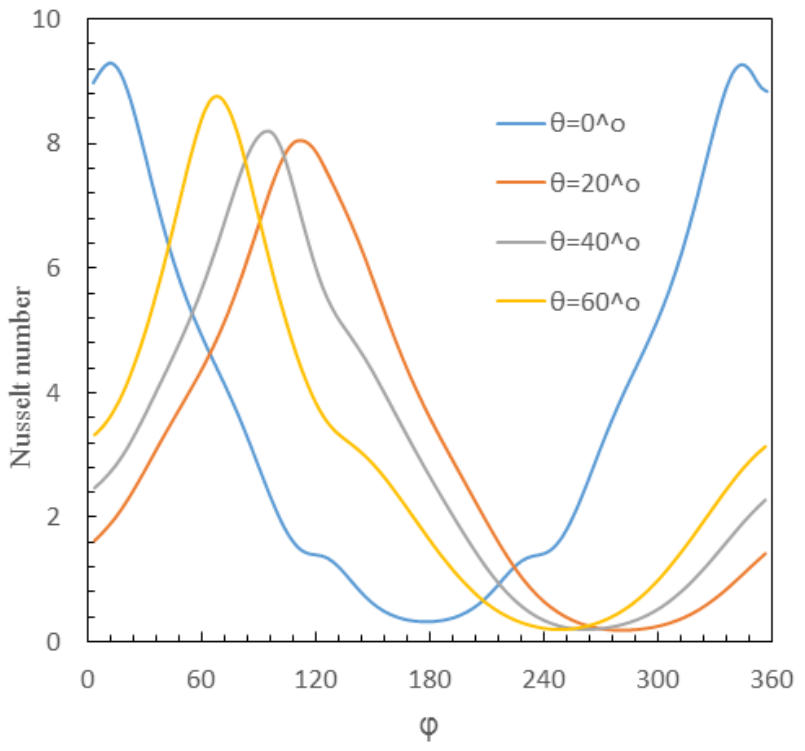

(a) $\mathrm{RR}=2$

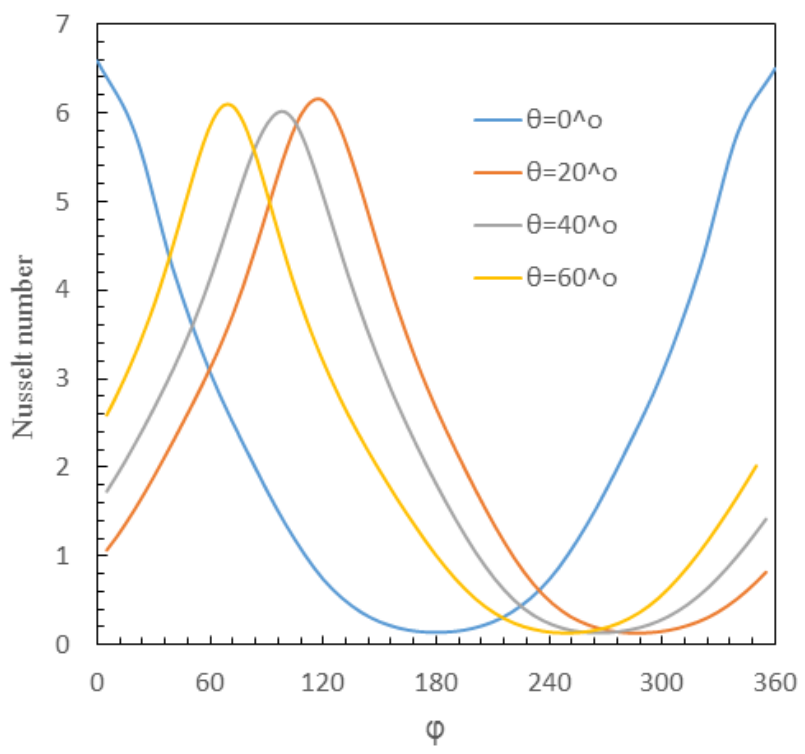

(b) $\mathrm{RR}=3$

Figure 10. Effect of angle of triangular cylinder inclination on local Nusselt number along the inner surface of outer circular cylinder at $\mathrm{Ra}=10^{5}$.

\section{Average nusselt number}

Figure 11 shows the linear relation between logarithmic average Nusselt number of outer circular cylinder and logarithmic Rayleigh number for different radius ratios. The correlations of average Nusselt number are given in Equations (8-11) for $\operatorname{Pr}=0.71$ and $\mathrm{Ra}=10^{3}-10^{7}$. It is shown that the exponent of Ra increases as radius ratio increases. Variations of the average Nusselt number with different angles of triangular cylinder inclination at constant Rayleigh number $\left(\mathrm{Ra}=10^{5}\right)$ and different radius ratios are shown in Figure 12. It is evident that there is no effect for inclination angles on the average Nusselt number values which nearly remain constant and increase as RR decreases. This result is logic because of decreasing the gap between the enclosure and the inner cylinder at constant heat transfer rates.

The correlations of average Nusselt number as a function of Rayleigh number for different radius ratios are given as follows:

$$
\begin{aligned}
& \overline{N u}=0.869 R a^{0.1408} \quad \text { for } R R=1.5 \\
& \overline{N u}=0.701 R a^{0.1684} \quad \text { for } R R=2.0 \\
& \overline{N u}=0.585 R a^{0.1885} \quad \text { for } R R=2.5 \\
& \overline{N u}=0.568 R a^{0.1859} \quad \text { for } R R=3.0
\end{aligned}
$$

The general equation of Nusselt number as a function of radius ratio and Rayleigh number at any angle of triangle inclination has been deduced as follows:

$$
\overline{N u}=0.55 R R^{0.4} R a^{0.1819}
$$


Journal of Thermal Engineering, Research Article, Vol. 7, No. 1, pp.240-254, January, 2021

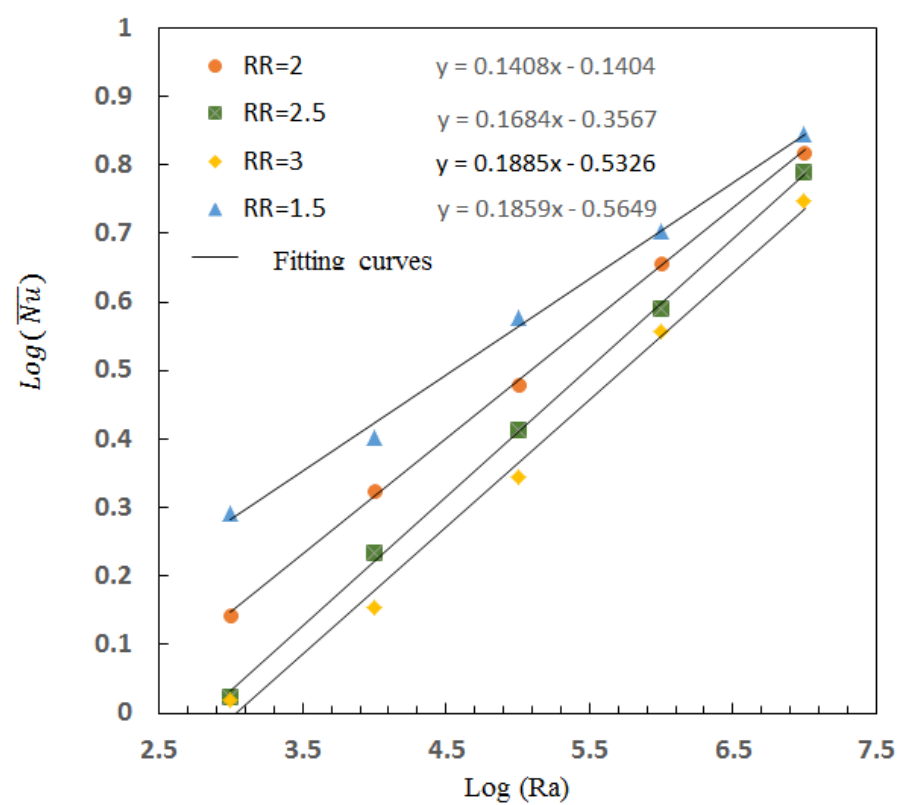

Figure 11. Logarithmic average Nusselt number versus logarithmic Rayleigh number for different radius ratios.

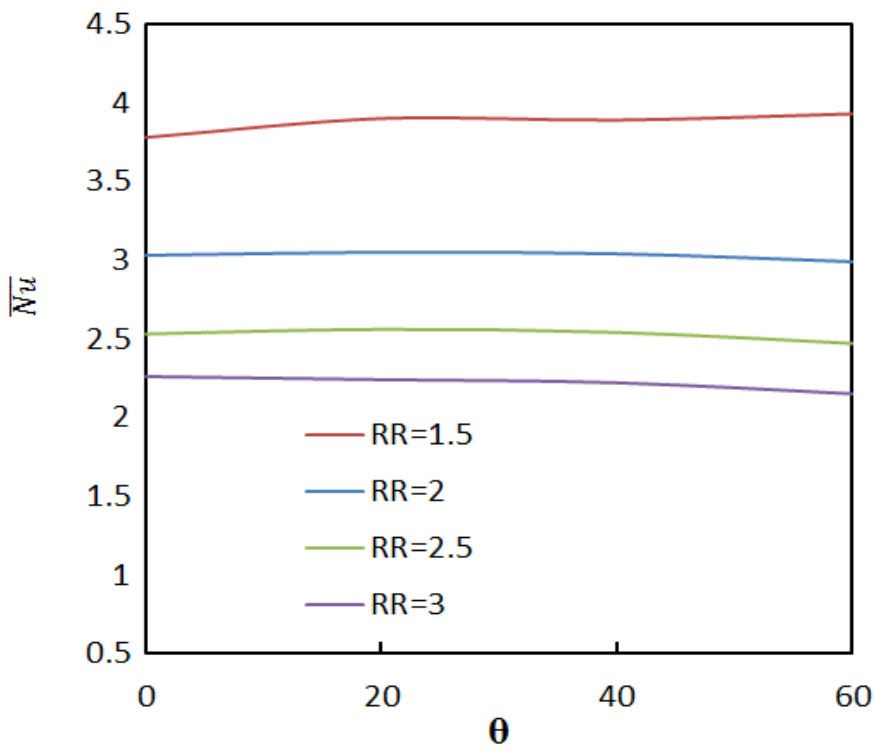

Figure 12. Average Nusselt number versus angles of triangle inclination ( $\theta$ in degree) at $\mathrm{Ra}=10^{5}$ and different radius ratios.

\section{CONCLUSION}

A simulation study of steady laminar free convection heat transfer around a hot triangular cylinder enclosed by a cold circular enclosure has been investigated. Some concluding remarks based on the results of present study can be given as follows:

1. As Rayleigh number increases, the streamlines become more concentrated next to the walls and the center of vortex displays upward towards the central plane of enclosure.

2. The distortion occurs in the streamlines as radius ratio decreases.

3. The separation of boundary layer near the left vertex of the triangular cylinder produces a small recirculating cell at $\theta=20^{\circ}$ if the radius ratio decreases to 1.5 . 
4. The boundary layer separation becomes more pronounced with increasing Rayleigh number and decreasing radius ratio.

5. As the Rayleigh number decreases, the isotherms become more flat at the lower surface of triangle.

6. At constant value of Rayleigh number, the thermal plum length is more decreased with decreasing radius ratio at expense increasing the isotherm lines under the base of triangular cylinder.

7. The conduction heat transfer mode is dominated at the bottom wall of circular cylinder for all radius ratios and inclination angles.

8. There is no effect for the inclination angle on the peak values of Nusselt number except the positions of these peaks due to turning of thermal plumes.

9. There is no effect for inclination angle on the average Nusselt number.

\section{NOMENCLATURE}

\begin{tabular}{ll}
$c_{p}$ & specific heat $(\mathrm{kJ} / \mathrm{kg} . \mathrm{K})$ \\
$D a$ & Darcy number \\
$g$ & gravitational acceleration $\left(\mathrm{m} / \mathrm{s}^{2}\right)$ \\
$h$ & heat transfer coefficient $\left(\mathrm{W} / \mathrm{m}^{2} \cdot \mathrm{K}\right)$ \\
$H a$ & Hartmann number \\
$k$ & thermal conductivity $(\mathrm{W} / \mathrm{m} . \mathrm{K})$ \\
$L$ & characteristic length, $\mathrm{L}=\mathrm{R}_{\mathrm{o}}-\mathrm{R}_{\mathrm{i}}(\mathrm{m})$ \\
$n$ & the normal direction with respect to the enclosure \\
$\mathrm{Nu}$ & Local Nusselt number \\
\hline$N u$ & average Nusselt number \\
$p$ & thermodynamic pressure $(\mathrm{Pa})$ \\
$P$ & dimensionless thermodynamic pressure \\
$P r$ & Prandtl number, $\frac{\vartheta}{\alpha}$ \\
$R a$ & Rayleigh number \\
$R_{\mathrm{i}}$ & radius of inner triangular cylinder $(\mathrm{m})$ \\
$R_{o}$ & radius of outer circular cylinder $(\mathrm{m})$ \\
$R R$ & radius ratio, $\mathrm{R}_{\mathrm{o}} / \mathrm{R}_{\mathrm{i}}$ \\
$T$ & temperature $\left({ }^{\circ} \mathrm{C}\right)$ \\
$T^{+}$ & dimensionless temperature \\
$u$ & velocity in $\mathrm{x}-$ direction $(\mathrm{m} / \mathrm{s})$ \\
$U$ & dimensionless velocity in $\mathrm{x}$ direction \\
$v$ & velocity in y-direction $(\mathrm{m} / \mathrm{s})$ \\
$V$ & dimensionless velocity in y direction \\
$x \& y$ & coordinates axis \\
&
\end{tabular}

Greek symbols
$\alpha$
$\beta$
$\theta$
$\varphi$
$\phi$
$\gamma$
$v$
$\mu$
$\rho$
$\kappa$

$\begin{array}{ll}\text { Subscripts } & \\ h & \text { hot } \\ c & \text { cold } \\ f & \text { fluid }\end{array}$

hot

fluid thermal diffusivity $\left(\mathrm{m}^{2} / \mathrm{s}\right)$

volume coefficient of expansion $\left(\mathrm{k}^{-1}\right)$

angle of triangular cylinder inclination (degree)

polar coordinate (degree)

volume fraction of nano-particles

magnetic field inclination angle

kinematical viscosity $\left(\mathrm{m}^{2} / \mathrm{s}\right)$

dynamic viscosity (Pa.s)

density $\left(\mathrm{kg} / \mathrm{m}^{3}\right)$

thermal conductivity $\left(\mathrm{W} / \mathrm{m}^{2}{ }^{\circ} \mathrm{C}\right)$ 
Journal of Thermal Engineering, Research Article, Vol. 7, No. 1, pp.240-254, January, 2021

\section{REFERENCES}

[1] Esam MA. Natural convection flow in a horizontal annulus with an oscillating inner cylinder using Lagrangian-Eulerian kinematics. Computers \& Fluids 2008; 37: 1253-1261..

[2] Varol Y, Oztop HF, Koca A., Ozgen F. Natural convection and fluid flow in inclined enclosure with a corner heater. Applied Thermal Engineering 2009; 29: 340-350.

[3] Ogut EB. Natural convection of water-based nanofluids in an inclined enclosure with a heat source. International Journal of Thermal Sciences 2009; 48: 2063-2073.

[4] Xu X, Zitao Y, Yacai H, Liwu F, Kefa C. A numerical study of laminar natural convective heat transfer around a horizontal cylinder inside a concentric air-filled triangular enclosure", International Journal of Heat and Mass Transfer 2010; 53: 345-355.

[5] Zi-Tao Y, Li-Wu F, Ya-Cai H, Ke-Fa C. Prandtl number dependence of laminar natural convection heat transfer in a horizontal cylindrical enclosure with an inner coaxial triangular cylinder. International Journal of Heat and Mass Transfer 2010; 53: 1333-1340.

[6] Revnic C, Grosan T, Pop I, Ingham DB. Magnetic field effect on the unsteady free convection flow in a square cavity filled with a porous medium with a constant heat generation. International Journal of Heat and Mass Transfer 2011; 54: 1734-1742.

[7] Wang H, Sun C, Xia XL, Tan H. Numerical investigation of laminar natural convection in a circular enclosure with a rectangle cylinder. Authorized licensed use limited to: IEEE Xplore. Downloaded on August 13, 2011 at 13:42:16 UTC from IEEE Xplore. Restrictions apply.

[8] Sheikholeslami M, Gorji-Bandpy M, Ganji DD, Soheil Soleimani, Seyyedi SM.. Natural convection of nanofluids in an enclosure between a circular and a sinusoidal cylinder in the presence of magnetic field", International Communications in Heat and Mass Transfer 2012; 39: 1435-1443.

[9] Khozeymehnezhad H, Mirbozorgi SA. Comparison of Natural Convection around a Circular Cylinder with a Square Cylinder Inside a Square Enclosure. Journal of Mechanical Engineering and Automation 2012; 2(6): 176-183.

[10] Roslan R, Saleh H, Hashim I. Natural Convection in a Differentially Heated Square Enclosure with a Solid Polygon. Hindawi Publishing Corporation,The Scientific World Journal, 2014, Article ID 617492, 11 pages, http://dx.doi.org/10.1155/2014/617492.

[11] Hussein AK, Rout SK. Natural convection in a triangular top wall enclosure with a solid strip. Journal of Engineering Science and Technology 2015; 10(10): 1326 - 1341.

[12] Yuan X, Tavakkoli F, and Vafai K. Analysis of natural convection in horizontal concentric annuli of variable inner shape. Numerical Heat Transfer 2015; Part A, 68: 1155-1174.

[13] Sharma A, Kumar S. Analysis of heat transfer and flow due to natural convection around heated semi-circular cylinder placed at incidences inside a square cavity. International Journal of Advance Research in Science and Engineering. Sep. 2017; 6,(2), ICITTESE-17: 330-337.

[14] Krunal GM, Manikandan B. Laminar natural convection characteristics in an enclosure with heated hexagonal block for non-Newtonian power law fluids. Chinese Journal of Chemical Engineering 2017; 25: 555-571.

[15] Alsabery AI, Sheremet MA, Chamkha AJ, Hashim I. Conjugate natural convection of Al 2 O 3 -water nanofluid in a square cavity with a concentric solid insert using Buongiorno 's two-phase model. International Journal of Mechanical Sciences 2018; 136: 200-219.

[16] Sivaraj C, Sheremet MA. MHD natural convection and entropy generation of ferrofluids in a cavity with a non-uniformly heated horizontal plate, International Journal of Mechanical Sciences., December 2018; 149: 326-337.

[17] Abbassi MA, Djebali R, Guedri K. Effects of heater dimensions on nanofluid natural convection in a heated incinerator shaped cavity containing a heated block. Journal of Thermal Engineering. April 2018; 4(3): 20182036.

[18] Geridönmez BP. Numerical simulation of natural convection in a porous cavity filled with freeofluid in presence of magnetic source. Journal of Thermal Engineering. Feb. 2018; 4(2), Special Issue: 1756-1769.

[19] Dogonchi AS, Sheremet MA, Ganji DD, Pop I. Free convection of copper-water nanofluid in a porous gap between hot rectangular cylinder and cold circular cylinder under the effect of inclined magnetic field. Journal of Thermal Analysis and Calorimetry 2019; 135: 1171-1184. 